\title{
ERRATUM
}

\section{Erratum to: Single-Dose Oritavancin Treatment of Acute Bacterial Skin and Skin Structure Infections: SOLO Trial Efficacy by Eron Severity and Management Setting}

Daniel H. Deck · Jennifer M. Jordan · Thomas L. Holland · Weihong Fan •

Matthew A. Wikler · Katherine A. Sulham · G. Ralph Corey

Published online: August 26, 2016

(C) The Author(s) 2016. This article is published with open access at Springerlink.com

Erratum to: Infect Dis Ther (2016)

DOI 10.1007/s40121-016-0119-9

Following publication of the aforementioned article, the authors noted a minor error in Table 1 and two small errors in Table 2. In Table 1, the Eron Class III Clinical Criteria should read $\mathrm{CrCl}<30 \mathrm{~mL} / \mathrm{min}$ or on dialysis, not $\mathrm{CrCl}<20 \mathrm{~mL} / \mathrm{min}$. In Table 2, Distribution of SOLO patients in modified Eron Classes I-III, the number of outpatients receiving vancomycin (VAN) in Class I should be 111 , not 11 . The total number of inpatients (Class I-III) was omitted, $n=1143$ (59.8\%).

The online version of the original article can be found under doi:10.1007/s40121-016-0119-9.

D. H. Deck $(\varangle) \cdot$ J. M. Jordan $(\varangle) \cdot$ W. Fan ·

M. A. Wikler - K. A. Sulham

The Medicines Company, Parsippany, NJ, USA

e-mail: Daniel.Deck@THEMEDCO.com

J. M. Jordan

e-mail: Jennifer.jordan@themedco.com

T. L. Holland · G. Ralph Corey

Duke University Hospital, Durham, NC, USA 
Table 1 Clinical criteria used to define modified Eron Classes I-IV

\begin{tabular}{|c|c|}
\hline Eron class & Clinical criteria \\
\hline \multirow[t]{2}{*}{ IV } & Bacteremia (positive blood culture); or \\
\hline & Absolute total neutrophils count $<500$ \\
\hline \multirow[t]{5}{*}{ III } & Meeting SIRS criteria \\
\hline & $\mathrm{CrCl}<30 \mathrm{~mL} / \mathrm{min}$ or on dialysis \\
\hline & ALT/AST >10-times ULN \\
\hline & Heart rate $>90 / \mathrm{min}$, breath rate $>20 / \mathrm{min}$, or systolic $\mathrm{BP}<90 \mathrm{mmHg}$; or \\
\hline & Cancer \\
\hline \multirow[t]{9}{*}{ II } & Age $\geq 75$ years old \\
\hline & Glucose $>11.1 \mathrm{mmol} / \mathrm{L}$ \\
\hline & Congestive heart failure at the randomization \\
\hline & $30 \mathrm{~mL} / \mathrm{min}<\mathrm{CrCl}<60 \mathrm{~mL} / \mathrm{min}$ \\
\hline & Hepatitis (excluding AST/ALT >10-times ULN) \\
\hline & Peripheral vascular disease \\
\hline & Diabetes mellitus \\
\hline & Fever (temperature $>38.0^{\circ} \mathrm{C}$ ); or \\
\hline & $\mathrm{BMI} \geq 30 \mathrm{~kg} / \mathrm{m}^{2}$ \\
\hline I & For the patients who didn't meet Classes II-IV \\
\hline
\end{tabular}

$A L T$ alanine transaminase, $A S T$ aspartate transaminase, $B M I$ body mass index, $B P$ blood pressure, $C r C l$ creatinine clearance, SIRS systemic inflammatory response syndrome, $U L N$ upper limit of normal

Table 2 Distribution of SOLO patients in modified Eron Classes I-III (mITT population, $n=1959$ )

\begin{tabular}{lllll}
\hline & Class I & Class II & Class III & Total (Class I-III) \\
\hline SOLO mITT $(n=1959)$ & $520(26.5 \%)$ & $790(40.3 \%)$ & $600(30.6 \%)$ & 1910 \\
Inpatients, $n(\%)$ & $301(57.9 \%)$ & $431(54.6 \%)$ & $411(68.5 \%)$ & $1143(59.8 \%)$ \\
ORI, $n$ & 144 & 224 & 203 & 571 \\
VAN, $n$ & 157 & 207 & 208 & 572 \\
Outpatients, $n(\%)$ & $219(42.1 \%)$ & $359(45.4 \%)$ & $189(31.5 \%)$ & $767(40.2 \%)$ \\
ORI, $n$ & 108 & 182 & 89 & 379 \\
VAN, $n$ & 111 & 177 & 100 & 388 \\
\hline
\end{tabular}

$m I T T$ modified intent-to-treat, $O R I$ oritavancin, $V A N$ vancomycin 
Open Access. This article is distributed under the terms of the Creative Commons AttributionNonCommercial 4.0 International License (http://creativecommons.org/licenses/by-nc/4. $0 /$ ), which permits any noncommercial use, distribution, and reproduction in any medium, provided you give appropriate credit to the original author(s) and the source, provide a link to the Creative Commons license, and indicate if changes were made. 